\title{
Association Between the Occurrence of Adverse Drug Events and Modification of First-Line Highly Active Antiretroviral Therapy in Ghanaian HIV Patients
}

\author{
Raymond A. Tetteh ${ }^{1,2} \cdot$ Edmund T. Nartey ${ }^{3,4} \cdot$ Margaret Lartey $^{5} \cdot$ \\ Aukje K. Mantel-Teeuwisse ${ }^{1}$ - Hubert G. M. Leufkens ${ }^{1,6}$. \\ Barbara A. Yankey ${ }^{7} \cdot$ Alexander N. O. Dodoo $^{3}$
}

Published online: 15 September 2016

(c) The Author(s) 2016. This article is published with open access at Springerlink.com

\begin{abstract}
Introduction Patients initiated on highly active antiretroviral therapy (HAART) generally remain on medication indefinitely. A modification in the HAART regimen may become necessary because of possible acute or chronic toxicities, concomitant clinical conditions, development of virological failure or the advent of adverse drug events. The study documents adverse drug events of HIV-positive Ghanaian patients with HAART modifications. It also investigates the association between documented adverse drug events and HAART modification using an unmatched case-control study design.

Method The study was conducted in the Fevers Unit of the Korle $\mathrm{Bu}$ Teaching Hospital and involved patients who
\end{abstract}

Raymond A. Tetteh

r_niiatetteh@yahoo.com

1 Utrecht Institute for Pharmaceutical Sciences, Utrecht University, Utrecht, The Netherlands

2 Pharmacy Department, Korle Bu Teaching Hospital, Korle$\mathrm{Bu}$, Accra, Ghana

3 World Health Organization Collaborating Centre for Advocacy and Training in Pharmacovigilance, Centre for Tropical Clinical Pharmacology and Therapeutics, School of Medicine and Dentistry, University of Ghana, Legon, Ghana

4 Department of Epidemiology and Disease Control, School of Public Health, University of Ghana, Legon, Ghana

5 Department of Medicine, School of Medicine and Dentistry, University of Ghana, Legon, Ghana

6 Medicines Evaluation Board, Utrecht, The Netherlands

7 School of Public Health, Georgia State University, Atlanta, USA attended the HIV Care Clinic between January 2004 and December 2009. Data from 298 modified therapy patients (cases) were compared with 298 continuing therapy patients (controls) who had been on treatment for at least 1 month before the end of study. Controls were sampled from the same database of a cohort of HIV-positive patients on HAART, at the time a case occurred, in terms of treatment initiation \pm 1 month. Data were obtained from patients' clinical folders and the HIV clinic database linked to the pharmacy database. The nature of the documented adverse drug events of the cases was described and the association between the documented adverse drug events and HAART modification was determined by logistic regression with reported odds ratios (ORs) and their $95 \%$ confidence interval $(\mathrm{CI})$.

Results Among the 298 modified therapy patients sampled in this study, $52.7 \%$ of them had at least one documented adverse drug event. The most documented adverse drug event was anaemia, recorded in $18.5 \%$ of modified therapy patients, all of whom were on a zidovudine-based regimen. The presence of documented adverse drug events was significantly associated with HAART modification [adjusted OR $=2.71$ (95 \% CI 2.11-3.48), $p<0.001]$.

Conclusion Among HIV patients on HAART, adverse drug events play a major role in treatment modification. Occurrence of adverse drug events may be used as a predictor for possible therapy modification. We recommend the institution of active pharmacovigilance in HIV treatment programmes as it permits the proper identification and characterisation of drug-related adverse events. This can help develop approaches towards their management and also justify therapy modifications. 


\section{Key Points}

Adverse drug events lead to highly active antiretroviral therapy (HAART) regimen modification.

Active pharmacovigilance systems should be emphasised to identify and characterise drug-related adverse events in HAART-treatment patients.

\section{Introduction}

Patients started on highly active antiretroviral therapy (HAART) generally remain on medication indefinitely. The World Health Organization (WHO) recommends firstline regimens involving two nucleoside reverse transcriptase inhibitors (NRTIs) and one non-nucleoside reverse transcriptase inhibitor (NNRTI) antiretroviral (ARV) drug $[1,2]$. Second-line regimens are started when the first-line regimens are ineffective. The provision of second-line regimens in resource-limited settings is generally a challenge $[3,4]$.

Therapy modifications in ARV regimens become necessary because of possible acute or chronic toxicities, concomitant clinical conditions, development of virological failure or the advent of adverse drug events. Drug substitution is defined as the replacement of one or more drugs in the first-line ARV regimen (NRTI or NNRTI) with another drug from the same ARV class (NRTI or NNRTI), e.g. the substitution of nevirapine (NVP) with efavirenz (EFV) or the substitution of an NRTI, stavudine (d4T), with zidovudine (ZDV). Therapy switch on the other hand refers to the change from the first-line NRTI-based HAART to a second-line protease inhibitor-based ARV regimen $[1,5]$.

A major constraint of HAART is the high prevalence of adverse drug events among patients receiving HAART. Adverse drug events are a very common complication of ARV therapy and a major reason for patients defaulting during HIV therapy [6]. The incidence is high in the initial stages, but tends to decrease later, though long-term events such as lipodystrophy may occur [7,8]. Up to $25 \%$ of patients discontinue their initial HAART regimen because of treatment failure, toxic effects or non-adherence within the first 12 months of therapy [6,9]. This poses a huge challenge in the fight against HIV. While research for less toxic ARVs continue, it is important to monitor treatmentassociated toxicities with a view to understanding and managing them where possible.
The approach to patients who need HAART modification depends on several factors. These include the reason for change, previous HAART experience, available treatment options and the tolerability of the HAART. In addition, adverse drug events associated with some ARVs (e.g. lipodystrophy, anaemia, renal impairment) further limit the type of ARVs that can be administered to patients $[10,11]$. Adverse drug events, if not managed effectively, will lead to medication non-adherence and invariably to treatment failure [10, 11].

In Ghana, the Korle Bu Teaching Hospital (KBTH) has been providing HAART services to patients living with HIV/AIDs (PLWHA) since 2003 at a token fee of US $\$ 3.00$ in response to the WHO " 3 by 5 " initiative for all nations, with the objective of placing 3 million persons living with HIV on HAART by 2005 [12]. As at 2015, about 11,000 people living with HIV/AIDS were on HAART in the KBTH, with some on treatment for the past 11 years. No singular effort has been made to analyse the factors associated with HAART modification from the data generated so far. There is also limited local data on the profile of adverse drug events. Determining the various factors associated with HAART modification and profiling the adverse drug events in patients on ARVs is an important step to the success of any HAART programme.

The study was in two parts; the first part describes all adverse drug events documented at most 12 months prior to therapy modification in HIV-positive patients who modified HAART at the KBTH in Accra, Ghana, and the second part determines the association between the presence of adverse drug events as a primary exposure and HAART modification as the outcome.

\section{Methods}

\subsection{Setting}

This study was conducted in the Fevers Unit of the KBTH, the premier teaching hospital in Ghana. As of December 2009, about 4850 patients have been initiated on HAART, with about 3440 of them still on treatment. There are three major outpatient clinic days per week, each with an average attendance of 120 patients. As at the time of study, the total number of therapy modifications was about 400 cases. Patients included in the study attended the HIV Care Clinic between January 2004 and December 2009. The HIV clinic runs an electronic database, which served as the source of data. The first-line HAART guidelines in place during the study period were either $\mathrm{d} 4 \mathrm{~T}+$ lamivudine $(3 \mathrm{TC})+\mathrm{NVP}$ or $\mathrm{d} 4 \mathrm{~T}+3 \mathrm{TC}+\mathrm{EFV}$ or $\mathrm{ZDV}+3 \mathrm{TC}+\mathrm{NVP}$ or $\mathrm{ZDV}+$ $3 \mathrm{TC}+\mathrm{EFV}$, i.e. $\mathrm{d} 4 \mathrm{~T} / 3 \mathrm{TC} / \mathrm{NVP}$ or $\mathrm{d} 4 \mathrm{~T} / 3 \mathrm{TC} / \mathrm{EFV}$ or $\mathrm{ZDV} /$ $3 \mathrm{TC} / \mathrm{NVP}$ or ZDV/3TC/EFV. HAART classification as 
first line or second line was based on the recommendations of the "Guidelines for Antiretroviral Therapy in Ghana" [5]. Regimens in this study are either d4T-based regimens or ZDV-based regimens depending on the type of NRTI involved.

\subsection{Study Design and Patient Population}

This is an unmatched case-control study using data documented in patients' clinical folders during previous hospital visits. The study used data from 298 modified therapy patients (cases) and 298 continuing therapy patients (controls) who had been on HAART between January 2004 and December 2009 and had been on treatment at least 1 month before the end of study. Only patients 15 years or older who were enrolled at the Fevers Unit of the KBTH, were on triple therapy and had available clinical and pharmacy records were included in the study. Cases were defined as patients aged 15 years or older who were on modified HAART (modified therapy patients). Changes in dose were not considered as modified therapy. Controls were defined as patients aged 15 years or older who were still on their initiating HAART (continuing therapy patients). Controls were sampled from the same database of a cohort of HIVpositive patients on HAART at the time a case occurred in terms of treatment initiation \pm 1 month. Given that cases and controls were sampled based on treatment initiation date, every risk pair had a similar period of observation.

A sample size of 298 each for cases and controls was determined as described by Strom [13], with the following assumptions: $10 \%$ expected prevalence of adverse drug events in the controls, a minimum odds ratio (OR) of 2.0 to be detected, a type I error of $5 \%$, a type II error of $20 \%$ (power of $80 \%$ ) and a ratio of cases to controls of $1: 1$.

\subsection{Data Collection and Definitions}

The outcome variable in this study was HAART modification (i.e. patients who modified initiating ARV therapy compared with patients who continued with initiating ARV), whilst the primary exposure of interest was documented adverse drug events at most 12 months prior to end of study. Data were obtained from patients' clinical folders and the HIV clinic database linked to the pharmacy database. We extracted documented adverse drug events from the clinical folders of patients as recorded by the attending physician during patients' follow-up post-treatment initiation. The clinical folder was designed by the National AIDS Control Programme (NACP) [5] for the Ghana Health Service in accordance with recommendations from the WHO, and has specific adverse drug event sections to be completed by the attending specialist physician on each patient's clinic visit. All trained HIV care physicians at all
HIV care centres nationwide use this specifically designed clinical folder for every HIV-positive patient on each clinic visit. A sub-section of this clinical folder lists the following adverse drug events for the attending physician to look out for or examine on each clinic visit of the patient; anaemia, rash, diarrhoea ( $>3$ days), pancreatitis, hepatotoxicity, pain/numbness/tingling in extremities, blood in urine, lipodystrophy and depression in addition to other adverse drug event(s) noticed [5]. For the purposes of this study, all adverse drug events documented in the clinical folder at most 12 months prior to HAART modification or end of study were used in assessing the presence of adverse drug events. No causality assessment was done on the adverse drug events data retrieved from documented records. We collected data on socio-demographic, clinical, immunological and virological parameters of the study participants, including gender, education at baseline, marital status at baseline, source of funding health care and occupation at baseline. Clinical and immunological baseline data collected prior to initiation of HAART included presence of systemic signs and symptoms, CD4 count, WHO staging and type of HAART regimen administered. All data extraction from the clinical folders and the electronic database was done by a trained specialist clinical pharmacist, the lead author, using a standardised template that was piloted prior to study implementation to maintain uniformity.

\subsection{Data Analysis}

Data were double entered, cleaned and managed using Microsoft Access (Microsoft Corporation, Redmond, Washington, USA) and analysed using Stata $11.0^{\circledR}$ (College Station, Texas, USA). Data were expressed as frequencies and percentages for categorical variables. Documented adverse drug event data were reviewed and coded using Medical Dictionary for Regulatory Activities $\left(\right.$ MedDRA $^{\circledR}$ ) (Version 13.1) terminology and grouped by System Organ Class (SOC) Preferred Term (PT) according to therapy type. MedDRA is a clinically validated international medical terminology used by regulatory authorities, and it organises adverse events by SOC divided into high level group terms (HLGTs), high level terms (HLTs), PTs and lowest level terms (LLTs).

Continuous variables were reported as mean \pm standard deviation or median with interquartile (IQR) range if not normally distributed. The presence of documented adverse drug events was the primary exposure variable, whilst HAART modification is the outcome variable. Predictors of HAART modification were determined by logistic regression and reported as OR with corresponding $95 \%$ confidence interval (CI). Covariates for the multivariate analysis were selected by the change-in-estimate method 
such that variables that change the crude estimate of the association between documented adverse drug events and HAART modification by more than $10 \%$ were considered confounders $[14,15]$. All statistical tests were two-sided, and $p<0.05$ was considered statistically significant.

\section{Results}

\subsection{Study Population}

During the study period between January 2004 and December 2009, 400 patients had their HAART modified. The total number of participants in this study was 596 . Cases and controls were similar in socio-demographic characteristics: median age 43.0 years (IQR 36-51) in cases versus 43.0 years (IQR 36-52) in controls and a female population of $65.4 \%(n=195)$ in cases versus $64.4 \%(n=192)$ in controls (Table 1$)$.
Clinical characteristics of cases and controls are shown in Table 2. The median duration from initiation of therapy to end of study was 344.5 days (IQR 101.5-882.5) for the cases and 374 days (IQR 104.5-898.3) for the controls. At least one adverse drug event was documented in 157 $(52.7 \%, 95 \%$ CI $46.8-58.5)$ of the cases and $12(4.0 \%$, $95 \%$ CI 2.1-6.9) of the controls.

\subsection{Description of Documented Adverse Drug Events}

A review of the clinical folders of the cases indicated that 157 modified therapy patients $(52.7 \%)$ had at least one documented adverse drug event, 13 patients $(4.4 \%)$ had two documented adverse drug events and 144 patients (95.6\%) had one documented adverse drug event (Table 3). From Table 3, the most documented adverse drug event was anaemia (SOC red blood cell disorder), reported in $18.5 \%(n=55)$ of the modified therapy
Table 1 Socio-demographic baseline characteristics of case and control subjects

\begin{tabular}{|c|c|c|}
\hline Characteristics & Case subjects $[n(\%)]^{\mathrm{a}}$ & Control subjects $[n(\%)]^{c}$ \\
\hline Age at HAART initiation & $N=298$ & $N=298$ \\
\hline Median (interquartile range), years & $43(36-51)$ & $43(36-52)$ \\
\hline Gender & $N=298$ & $N=298$ \\
\hline Female & $195(65.4)$ & $192(64.4)$ \\
\hline Male & $103(34.6)$ & $106(35.6)$ \\
\hline Marital status & $N=293$ & $N=296$ \\
\hline Single & $63(21.5)$ & $55(18.6)$ \\
\hline Married/cohabiting & $159(54.3)$ & $160(54.0)$ \\
\hline Divorced/separated/widowed & $71(24.2)$ & $81(27.4)$ \\
\hline Educational status & $N=288$ & $N=295$ \\
\hline None & $42(14.6)$ & $41(13.9)$ \\
\hline Primary/junior high school & $132(45.8)$ & $137(46.4)$ \\
\hline Senior high school & $87(30.2)$ & $92(31.2)$ \\
\hline Tertiary & $27(9.4)$ & $25(8.5)$ \\
\hline Employment status & $N=284$ & $N=294$ \\
\hline Unemployed & $32(11.3)$ & $27(9.2)$ \\
\hline Employed & $252(88.7)$ & $267(90.8)$ \\
\hline Smoking & $N=293$ & $N=295$ \\
\hline Non-smoker & $273(93.2)$ & $278(94.2)$ \\
\hline Smoker & $20(6.8)$ & $17(5.8)$ \\
\hline Alcohol use & $N=293$ & $N=295$ \\
\hline Non-drinker & 239 (81.6) & $241(81.7)$ \\
\hline Drinker & $54(18.4)$ & $54(18.3)$ \\
\hline Source of funding & $N=289$ & $N=293$ \\
\hline Self & $180(62.3)$ & $203(69.3)$ \\
\hline National health insurance and other sources & 109 (37.7) & $90(30.7)$ \\
\hline
\end{tabular}

HAART highly active antiretroviral therapy

${ }^{\text {a }}$ Data are reported as $n(\%)$ unless otherwise stated 
Table 2 Clinical characteristics of case and control subjects

\begin{tabular}{|c|c|c|}
\hline Characteristics & Case subjects $[n(\%)]^{\mathrm{a}}$ & Control subjects $[n(\%)]^{\mathrm{a}}$ \\
\hline Duration from HAART initiation to end of study & $N=298$ & $N=298$ \\
\hline Median (interquartile range), days & $344.5(101.5-882.5)$ & $374(104.5-898.3)$ \\
\hline Documented adverse event & $N=298$ & $N=298$ \\
\hline Present & $157(52.7)$ & $12(4.0)$ \\
\hline Absent & $141(47.3)$ & $286(96.0)$ \\
\hline WHO HIV stage at HAART initiation & $N=293$ & $N=296$ \\
\hline Stage I-III & $229(78.2)$ & $251(84.8)$ \\
\hline Stage IV & $64(21.8)$ & $45(15.2)$ \\
\hline BMI at HAART initiation & $N=240$ & $N=240$ \\
\hline Underweight $\left(<18.00 \mathrm{~kg} / \mathrm{m}^{2}\right)$ & $76(31.7)$ & $51(21.3)$ \\
\hline Normal weight/overweight/obese $\left(\geq 18.00 \mathrm{~kg} / \mathrm{m}^{2}\right)$ & $164(68.3)$ & $189(78.7)$ \\
\hline Presence of systemic signs and symptoms at HAART initiation & $N=294$ & $N=298$ \\
\hline Yes & $163(55.4)$ & $128(43.0)$ \\
\hline No & $131(44.6)$ & $170(57.0)$ \\
\hline CD4 T lymphocytes count at HAART initiation & $N=293$ & $N=295$ \\
\hline$<150$ cells $/ \mathrm{mm}^{3}$ & $203(69.3)$ & $168(56.9)$ \\
\hline$\geq 150$ cells $/ \mathrm{mm}^{3}$ & $90(30.7)$ & $127(43.1)$ \\
\hline HAART regimen administered & $N=298$ & $N=298$ \\
\hline ZDV/3TC/EFV & $70(23.5)$ & $85(28.5)$ \\
\hline ZDV/3TC/NVP & $71(23.8)$ & $76(25.5)$ \\
\hline d4T/3TC/EFV & $84(28.2)$ & $63(21.1)$ \\
\hline $\mathrm{d} 4 \mathrm{~T} / 3 \mathrm{TC} / \mathrm{NVP}$ & $60(20.1)$ & $61(20.5)$ \\
\hline Others & $13(4.4)$ & $13(4.4)$ \\
\hline
\end{tabular}

$3 T C$ lamivudine, BMI body mass index, $d 4 T$ stavudine, $E F V$ efavirenz, $H A A R T$ highly active antiretroviral therapy, $N V P$ nevirapine, WHO World Health Organization, $Z D V$ zidovudine

${ }^{a}$ Data are reported as $n(\%)$ unless otherwise stated

patients. Metabolic and nutritional disorders were documented in $12.4 \%(n=37)$ of the modified therapy patients, whilst peripheral neuropathy was documented in $8.7 \%(n=26)$ of the modified therapy patients (Table 3$)$.

\subsection{Association Between Documented Adverse Drug Events and HAART Modification}

The presence of documented adverse drug events was significantly associated with HAART [crude $\mathrm{OR}=2.27$ $(95 \%$ CI 1.89-2.72)] in the univariate analysis (Table 4). Other factors associated with HAART modification in the univariate analysis were WHO HIV staging at HAART initiation, body mass index (BMI) at HAART initiation, presence of systemic signs and symptoms at HAART initiation and CD4 count at HAART initiation. However, when the change-in-estimate method was used to determine potential confounders to the association between documented adverse drug events and HAART modification, only BMI at HAART initiation changed the crude OR by $>10 \%$ and was thus included in the multivariate analysis. After adjusting for this possible confounder, the odds of HAART modification was 2.71 in patients with documented adverse drug events [adjusted OR $=2.71(95 \% \mathrm{CI}$ 2.11-3.48), $p<0.001]$.

Sub-group analysis of the outcome variable indicated significant association between documented adverse drug events and first-line to first-line HAART modification [adjusted OR $=2.88(95 \%$ CI 2.22-3.74), $p<0.001$ ], but no association with first-line to second-line HAART modification [adjusted OR $=2.33(95 \%$ CI $0.69-7.91)$, $p=0.175]$.

\section{Discussion}

\subsection{Profile of Documented Adverse Drug Events}

At least one adverse drug event was documented in $52.7 \%$ $(n=157)$ of modified therapy patients, as against $4 \%$ ( $n=12)$ of continuing therapy patients. Similar to other findings, anaemia, nutritional and metabolic disorders and peripheral neuropathy were the most documented adverse drug events $[11,16]$. The most documented adverse drug 


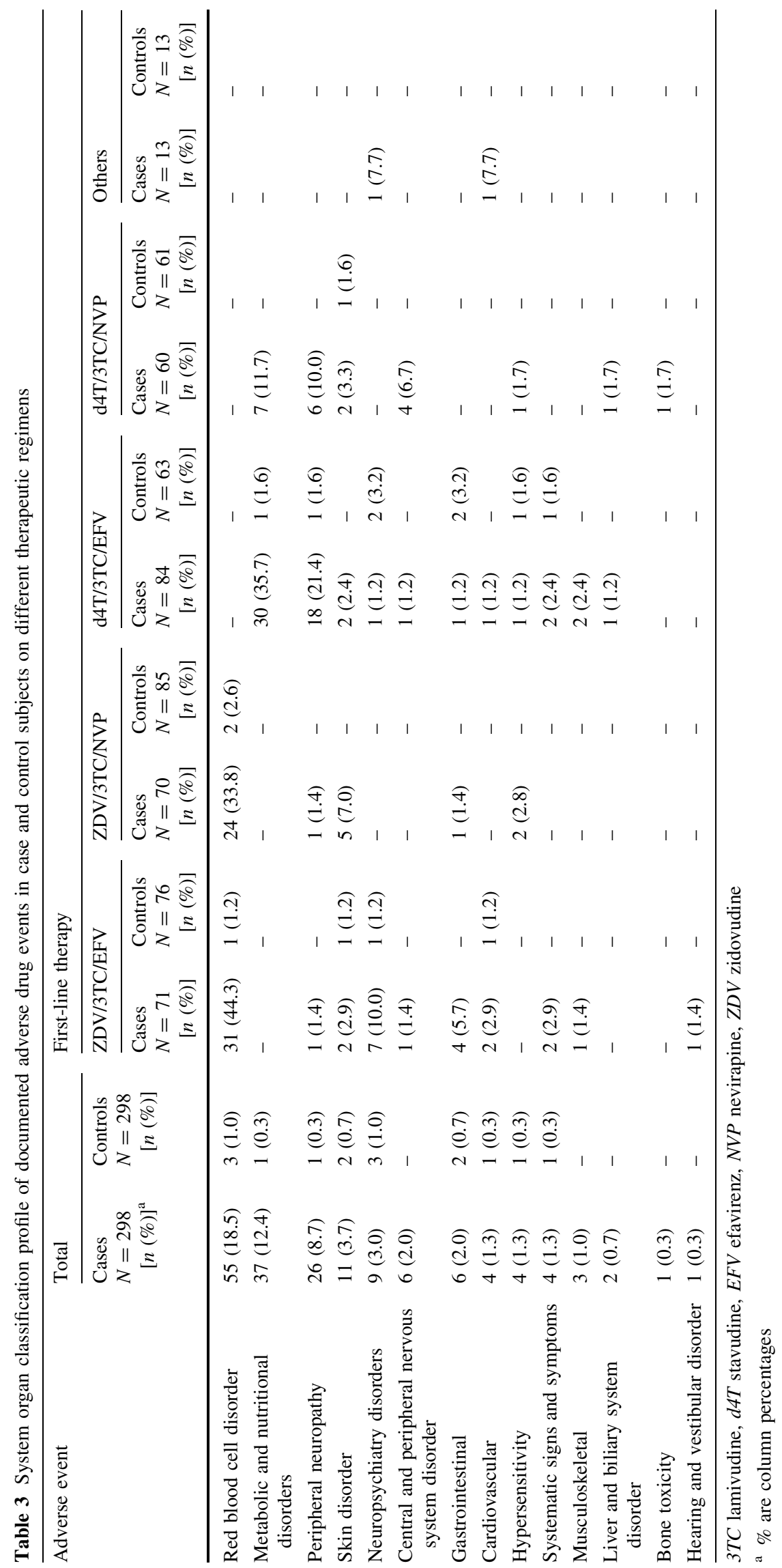


Table 4 Socio-demographic and clinical factors associated with HAART modification

\begin{tabular}{|c|c|c|c|c|c|}
\hline \multicolumn{2}{|l|}{ Characteristic } & \multirow{2}{*}{$\begin{array}{l}\text { Crude odds ratio } \\
{[95 \% \mathrm{CI}]} \\
1.00[0.99-1.02]\end{array}$} & \multirow{2}{*}{$\begin{array}{l}P \text { value } \\
0.884\end{array}$} & \multirow{2}{*}{$\begin{array}{l}\text { Adjusted odds ratio } \\
{\left[\begin{array}{llll}{[95 \%} & \mathrm{CI}\end{array}{ }^{\mathrm{a}}\right.} \\
-\end{array}$} & \multirow{2}{*}{$P$ value } \\
\hline Age at HAART initiation & & & & & \\
\hline \multirow[t]{2}{*}{ Gender } & Male & $0.96[0.68-1.34]$ & 0.797 & - & - \\
\hline & Female & 1.00 & & & \\
\hline \multirow[t]{2}{*}{ Smoking status } & Smoker & $1.20[0.62-2.34]$ & 0.596 & - & - \\
\hline & Non-smoker & 1.00 & & & \\
\hline \multirow[t]{2}{*}{ Alcohol use } & Drinker & $1.01[0.66-1.53]$ & 0.969 & - & - \\
\hline & Non-drinker & 1.00 & & & \\
\hline \multirow[t]{2}{*}{ Documented adverse drug event } & Present & $2.27[1.89-2.72]$ & $<0.001$ & $2.71[2.11-3.48]$ & $<0.001$ \\
\hline & Absent & 1.00 & & 1.00 & \\
\hline \multirow{2}{*}{$\begin{array}{l}\text { WHO HIV staging at HAART } \\
\text { initiation }\end{array}$} & IV & $1.56[1.02-2.37]$ & 0.039 & - & - \\
\hline & I-III & 1.00 & & & \\
\hline \multirow[t]{2}{*}{ BMI at HAART initiation } & Underweight $\left(<18.00 \mathrm{~kg} / \mathrm{m}^{2}\right)$ & $1.72[1.14-2.59]$ & 0.010 & $1.76[1.09-2.84]$ & 0.021 \\
\hline & $\begin{array}{l}\text { Normal/overweight/obese } \\
\left(\geq 18.00 \mathrm{~kg} / \mathrm{m}^{2}\right)\end{array}$ & 1.00 & & 1.00 & \\
\hline \multirow{2}{*}{$\begin{array}{l}\text { Systemic signs and symptoms at } \\
\text { HAART initiation }\end{array}$} & Present & $1.65[1.19-2.29]$ & 0.002 & - & - \\
\hline & Absent & 1.00 & & & \\
\hline \multirow{2}{*}{$\begin{array}{l}\text { CD4 T lymphocytes count at HAART } \\
\text { initiation }\end{array}$} & $<150$ cells $/ \mathrm{mm}^{3}$ & 1.71 [1.22-2.39] & 0.002 & - & - \\
\hline & $\geq 150$ cells $/ \mathrm{mm}^{3}$ & 1.00 & & & \\
\hline \multirow[t]{5}{*}{ HAART regimen administered } & ZDV/3TC/NVP & $1.13[0.72-1.78]$ & 0.585 & - & - \\
\hline & $\mathrm{d} 4 \mathrm{~T} / 3 \mathrm{TC} / \mathrm{EFV}$ & $1.62[1.03-2.55]$ & 0.038 & - & - \\
\hline & d4T/3TC/NVP & $1.19[0.74-1.92]$ & 0.465 & - & - \\
\hline & Others & $1.21[0.53-2.79]$ & 0.647 & - & - \\
\hline & ZDV/3TC/EFV & 1.00 & & & \\
\hline
\end{tabular}

$3 T C$ lamivudine, $B M I$ body mass index, $C I$ confidence interval, $d 4 T$ stavudine, $E F V$ efavirenz, $H A A R T$ highly active antiretroviral therapy, $N V P$ nevirapine, $W H O$ World Health Organization, $Z D V$ zidovudine

a Only variables that changed the association between documented adverse drug event and HAART modification by more than $10 \%$ were included in the multivariate analysis as cofounders

event among the entire study population was anaemia $(19.6 \%, n=58)$, mostly from the use of $\mathrm{ZDV}$, but which was totally absent in patients on $\mathrm{d} 4 \mathrm{~T}$-based therapy. A cohort study at the same study site cited anaemia as the most documented adverse drug event [11], similar to other studies [16]. Metabolic disturbances and peripheral neuropathy, the next most documented adverse drug events, were documented mostly in the $\mathrm{d} 4 \mathrm{~T}$-based therapies, but were totally absent in the ZDV-based therapies. Red blood cell disorders, metabolic and nutritional disorders and peripheral neuropathy were the three leading documented events. Among this group, practically all the people who had a documented red blood cell disorder had been given a ZDV combination. ZDV has long been known to cause anaemia, because of its myelosuppressive activity [17-20]. This haematological reaction occurs when ZDV is given in dosages of $\geq 1500 \mathrm{mg}$ daily. Lower dosages of ZDV are used in triple combination therapy as first-line to reduce this reaction. Use of other medications that inhibit cytochrome P450 may also enhance the side effects of ZDV since they can inhibit its hepatic metabolism [17, 21, 22]. Patients who experienced metabolic and nutritional disorders had been given a d4T combination. The majority of people who experienced peripheral neuropathy were also on $\mathrm{d} 4 \mathrm{~T}$, and they reported a greater variety of adverse drug events. These adverse drug events with $\mathrm{d} 4 \mathrm{~T}$ have been demonstrated in several studies [23-25]. Metabolic and nutritional disorders such as hyperlactataemia, lactic acidosis, lipoatrophy and in some cases hypertriglyceridaemia as well as hypercholesterolaemia [26] can lead to several cardiovascular diseases. Ter Hofsted et al. noted that these effects are also more pronounced with higher doses of $\mathrm{d} 4 \mathrm{~T}$ and recommend plasma monitoring of $\mathrm{d} 4 \mathrm{~T}$ as a way to prevent d4T-associated lipoatrophy [25].

Studies have shown that the most common adverse effects associated with discontinuation of HAART are gastrointestinal [6]. These commonly include anorexia, nausea, vomiting and diarrhoea. A pharmacovigilance study of adults on HAART in South Africa indicated that out of a total of 2585 patients monitored over a period of 
5 years, $34.5 \%$ had their initiation regimens changed and this substitution/switch occurred on average of 14.9 months after HAART initiation [27]. The study also showed that the four most common adverse drug events experienced by the patients who switched therapy due to ARV-related toxicity were polyneuropathy (24.0\%), lipodystrophy $(23.9 \%)$, neuropathy $(10.6 \%)$ and suspected lactic acidosis $(3.8 \%)$. Another study in a South African cohort indicated that the frequency of therapy switch (within 3 years of HAART initiation) due to NVP toxicity is about $8 \%$, EFV toxicity $2 \%$ and ZDV toxicity $8 \%$ [28]. The study also indicated that therapy switch due to d4T toxicity occurred in $21 \%$ of patients due to symptomatic hyperlactataemia $(5 \%)$, lipodystrophy $(9 \%)$ or peripheral neuropathy $(6 \%)$.

The high proportion of first-line to first-line HAART modification $(80.5 \%, n=240)$ versus first-line to secondline HAART modification $(19.5 \%, n=58)$ among the modified therapy patients participating in this study is similar to that reported in other studies in developed countries [29, 30]. The median duration of 344.5 days from HAART initiation to HAART modification is comparable with a southern Indian study on generic HAART modification of 406 days [31] and a South African study of 14.9 months (447 days) [27]. This indicates that patients fared generally well on the initiating regimen for at least a year before modification of therapy. The modifications could therefore be due to persistent adverse drug events, policy changes or treatment failures.

\subsection{Association Between Documented Adverse Drug Events and HAART Modification}

The presence of documented adverse drug events was significantly associated with HAART modification [adjusted OR $=2.71(95 \%$ CI 2.11-3.48), $p<0.001]$. This is in conformation with results from other studies that also indicated that the experience of adverse drug events is a very common reason for HAART modification in HIVpositive patients on HAART therapy [6, 32-38]. Clearly, the issue of the relationship between occurrence of adverse drug events and HAART modification is an extremely important one that deserves further concerted study across several countries and with a larger number of patients, especially considering the fact that HIV has now become a chronic condition, with patients likely to be on life-long therapy. In addition, the proportion of patients experiencing an adverse drug event before therapy modification in this study is similar to the proportions found in studies by Padua et al. in Brazil [35] and Tadesse et al. in Ethiopia [37], which indicated that 56.1 and $53.8 \%$, respectively, of patients who modified to another therapy self-reported at least one adverse drug reaction [35, 37]. A similar case- control study in Ethiopia, however, showed that as high as $85.7 \%$ of patients on HAART had changed therapy [32].

\subsection{Clinical and Policy Implications}

Adverse drug events associated with HAART have become a major public health concern, especially in relation to poor adherence to complex regimens in PLWHA [39]. Poor adherence to HAART due to experienced adverse drug events may even be prevalent regardless of the relationship of these events to HAART. It is therefore important to have an active pharmacovigilance programme in all HIV treatment programmes that permits the proper identification and characterisation of drug-related adverse events and to also develop approaches towards their management.

The presence of drug toxicity and/or poor medication adherence may limit any derived benefit from HAART and often results in therapy modifications which can be costly. HAART modification in resource-constrained settings like Ghana is costly as it narrows down on the regimen options available to patients, thereby posing a major challenge to the effectiveness of the ongoing treatment. This also poses challenges to the national programme, especially in the limited choice of regimens available to patients in this setting. In addition, although HAART modification could itself be an option for the management of adverse drug events, it can also lead to the development of new and severe adverse drug events, further complicating any future regimen options available.

In resource-limited settings, HIV clinics should closely monitor adverse drug events with both clinical and laboratory investigations in order to provide early interventions to mitigate any untoward HAART modification [31]. Most adverse drug events are determined clinically by the use of specific signs and symptoms, including fatigue with conjunctival pallor (due to ZDV-related anaemia), neuropsychiatric problems (due to EFV), peripheral wasting (due to d4T-related lipodystrophy) and rash (due to NVP, EFV or abacavir) [40]. At the $\mathrm{KBTH}$, patients undergo regular medical review, laboratory examinations, adherence counselling and general education on the disease and its management in order to overcome noncore HAART modifications. Adherence is reviewed at every clinic visit and documented, and is considered satisfactory when patients' self-report of compliance tallies with pill count. In addition, it will be important to establish standardised protocols for adverse drug event monitoring to improve the recognition, management and prevention of these events [41]. Management of adverse drug events including dose adjustment and the choice of appropriate regimen is a key strategy for improving adherence among HIV-positive patients on therapy and the avoidance of any subsequent therapy modification [42]. 
Tenofovir as an alternative to $\mathrm{ZDV}$ in potentially anaemic patients (baseline haemoglobin of $8-10 \mathrm{~g} / \mathrm{dL}$ ) is now the preferred first-option regimen choice in response to the toxic effects of ZDV. The finding that low CD4 counts $\left(<150\right.$ cells $\left./ \mathrm{mm}^{3}\right)$ at HAART initiation was associated with HAART modification in this study supports the current modified WHO recommendations that HAART should be started in patients with even high CD4 counts of 500 cells $/ \mathrm{mm}^{3}$ [43]. Adherence to this new WHO recommendation will ensure that patients initiated on HAART have lower odds of HAART modification and also the development of adverse drug events in the early stages of treatment. The current findings carry some clinical implications, which should be carefully considered in future studies, especially in African subjects who are prone to haemoglobinopathies and are more likely to develop adverse drug events with ZDV use [44]. The limited ARV regimen options may therefore present potential challenges to clinicians with time in resource-limited settings.

\subsection{Limitations}

A limitation of this study is that the findings cannot be generalised across all HIV treatment sites in Ghana since the study was localised to the KBTH. However, the literature review presents similarities with other studies done in Africa and beyond, thus rendering the study results worthwhile for any policy review. Self-reporting of adverse drug events by patients may have served as a limitation since the culture of spontaneous reporting of adverse drug events is absent in the African population and health professionals have to prompt reporting from most patients. Initial adherence counselling of patients should emphasise the reporting of all adverse drug events. Poor recordkeeping practices also served as a limitation in retrieving complete data sets on patients; therefore, the use of electronic data capture should be encouraged.

This study is further limited by the lack of routine baseline viral load determination, which could have served to confirm treatment failure in some patients and therefore the need for therapy switch. This could have served also as a predictor of therapy switch since patients with very high viral load tend to have low CD4 count and often present with relatively more severe opportunistic infections. Owing to resource challenges, random primary HAART resistance testing is not carried out at baseline or in a failing regimen; therefore, we were unable to determine what possible effect primary resistance to the ARVs in use might have had on our findings. Again no duplicate data extraction was done as it required another clinical pharmacist to be engaged specifically for that aspect of work, but efforts were made to ensure extracted data from the clinical folders matched with data from the electronic database.

\subsection{Conclusion}

These findings indicate that among HIV-positive patients on HAART, adverse drug events play a major role in treatment modifications (substitution or switch). Occurrence of adverse drug events may be used as a predictor for possible therapy modification. The institution of active pharmacovigilance in HIV treatment programmes permits the proper identification and characterisation of drug-related adverse events and can help to develop approaches towards their management and justified therapy modification. Monitoring adverse drug events and managing them appropriately may help to avoid dispensable therapy modifications.

Acknowledgements Daniel Ankrah, Elaine Dovi Awumee, Francisca Zigah-Hama and Dr. Joseph Oliver-Commey helped with data collection and database capture. Daniel Ankrah, Mary Nordor, Vera Botchway and Francisca Zigah-Hama assisted with editing and research advice. Drs. Nii Akwei Addo and Steve Ayisi-Addo of the NACP provided continuous support and prudent management of the NACP. The entire clinical care team worked together to generate the needed information.

Author Contribution The authors RAT, ETN, BAY and ML worked on the conception, study design and the final article composition. RAT, ETN, BAY, ML, AMT, HGML and ANOD contributed to the methods, results and the article's continuous critical review. ETN, BAY, RAT, AMT, ML, ANOD and HGML worked on the data analysis, discussions and critical revisions. RAT and ETN contributed equally and are co-first authors. All the authors read and approved the final manuscript.

\section{Compliance with Ethical Standards}

Sources of funding No sources of funding were used to assist in the preparation of this study.

Conflict of interest Raymond A. Tetteh, Edmund T. Nartey, Margaret Lartey, Aukje K. Mantel-Teeuwisse, Hubert G.M. Leufkens, Barbara A. Yankey and Alexander N.O. Dodoo have no conflicts of interest that are directly relevant to the content of this study.

Ethical approval Ethical approval for the study was obtained from the Ethical and Protocol Review Committee of the University of Ghana Medical School (UGMS) [MS-Et/M.6-P.5.3/2009-10].

Open Access This article is distributed under the terms of the Creative Commons Attribution-NonCommercial 4.0 International License (http://creativecommons.org/licenses/by-nc/4.0/), which permits any noncommercial use, distribution, and reproduction in any medium, provided you give appropriate credit to the original author(s) and the source, provide a link to the Creative Commons license, and indicate if changes were made.

\section{References}

1. WHO. HIV/AIDS Programme. Antiretroviral therapy for HIV infection in adults and adolescents in resource-limited settings: 
towards universal access. Recommendations for a public health response. World Health Organization.

2. Ivers LC, Kendrick D, Doucette K. Efficacy of antiretroviral therapy programs in resource-poor settings: a meta-analysis of the published literature. Clin Infect Dis. 2005;41(2):217-24 Epub 2005/06/29.

3. Boyd MA, Cooper DA. Second-line combination antiretroviral therapy in resource-limited settings: facing the challenges through clinical research. AIDS. 2007;21(Suppl 4):S55-63 Epub 2007/09/25.

4. Renaud-Thery F, Nguimfack BD, Vitoria M, Lee E, Graaff P, Samb B, et al. Use of antiretroviral therapy in resource-limited countries in 2006: distribution and uptake of first- and second-line regimens. AIDS. 2007;21(Suppl 4):S89-95 Epub 2007/09/25.

5. GHS, NACP. Guidelines for Antiretroviral Therapy in Ghana. GHS/ NACP 2010. Accra: Ghana Health Service, 2010.

6. O'Brien ME, Clark RA, Besch CL, Myers L, Kissinger P. Patterns and correlates of discontinuation of the initial HAART regimen in an urban outpatient cohort. J Acquir Immune Defic Syndr. 2003;34(4):407-14 Epub 2003/11/15.

7. Menezes de Pádua CA, César CC, Bonolo PF, Acurcio FA, Guimarães MDC. High incidence of adverse reactions to initial antiretroviral therapy in Brazil. Braz J Med Biol Res = Revista brasileira de pesquisas medicas e biologicas/Sociedade Brasileira de Biofisica [et al]. 2006;39(4):495-505.

8. Fellay J, Boubaker K, Ledergerber B, Bernasconi E, Furrer H, Battegay M, et al. Prevalence of adverse events associated with potent antiretroviral treatment: Swiss HIV Cohort Study. Lancet. 2001;358(9290):1322-7 Epub 2001/10/31.

9. Goldie SJ, Paltiel AD, Weinstein MC, Losina E, Seage GR 3rd, Kimmel AD, et al. Projecting the cost-effectiveness of adherence interventions in persons with human immunodeficiency virus infection. Am J Med. 2003;115(8):632-41 Epub 2003/12/06.

10. Inzaule S, Otieno J, Kalyango J, Nafisa L, Kabugo C, Nalusiba J, et al. Incidence and predictors of first line antiretroviral regimen modification in western Kenya. PloS One. 2014;9(4):e93106 (Epub 2014/04/04).

11. Lartey M, Asante-Quashie A, Essel A, Kenu E, Ganu V, Neequaye A. Adverse drug reactions to antiretroviral therapy during the early art period at a tertiary hospital in Ghana. Pan Afr Med J. 2014; 18:25 Epub 2014/11/05.

12. WHO. Treating 3 million by 2005: Making it happen-The WHO Strategy Geneva: World Health Organization, 2003.

13. Strom BL. Sample size considerations for pharmacoepidemiology studies. In: Strom BL, Kimmel SE, editors. Textbook of pharmacoepidemiology. London: Wiley; 2006. p. 25-33.

14. Greenland S. Modeling and variable selection in epidemiologic analysis. Am J Public Health. 1989;79(3):340-9 Epub 1989/03/01.

15. Maldonado G, Greenland S. Simulation study of confounder-selection strategies. Am J Epidemiol. 1993;138(11):923-36 (Epub 1993/12/01).

16. Curkendall SM, Richardson JT, Emons MF, Fisher AE, Everhard F. Incidence of anaemia among HIV-infected patients treated with highly active antiretroviral therapy. HIV Med. 2007;8(8):483-90 Epub 2007/10/20.

17. Dainiak N, Worthington M, Riordan MA, Kreczko S, Goldman L. 3'-Azido-3'-deoxythymidine (AZT) inhibits proliferation in vitro of human haematopoietic progenitor cells. $\mathrm{Br} \mathrm{J}$ Haematol. 1988;69(3):299-304 Epub 1988/07/01.

18. Moyle G, Sawyer W, Law M, Amin J, Hill A. Changes in hematologic parameters and efficacy of thymidine analoguebased, highly active antiretroviral therapy: a meta-analysis of six prospective, randomized, comparative studies. Clin Ther. 2004;26(1):92-7 Epub 2004/03/05.

19. Richman DD, Fischl MA, Grieco MH, Gottlieb MS, Volberding PA, Laskin OL, et al. The toxicity of azidothymidine (AZT) in the treatment of patients with AIDS and AIDS-related complex. A double-blind, placebo-controlled trial. $\mathrm{N}$ Engl $\mathrm{J}$ Med. 1987;317(4):192-7 Epub 1987/07/23.

20. Semba RD, Shah N, Klein RS, Mayer KH, Schuman P, Vlahov D. Prevalence and cumulative incidence of and risk factors for anemia in a multicenter cohort study of human immunodeficiency virus-infected and -uninfected women. Clin Infect Dis. 2002;34(2):260-6 Epub 2001/12/12.

21. de Miranda P, Good SS, Yarchoan R, Thomas RV, Blum MR, Myers CE, et al. Alteration of zidovudine pharmacokinetics by probenecid in patients with AIDS or AIDS-related complex. Clin Pharmacol Ther. 1989;46(5):494-500 Epub 1989/11/01.

22. Sim SM, Back DJ, Breckenridge AM. The effect of various drugs on the glucuronidation of zidovudine (azidothymidine; AZT) by human liver microsomes. Br J Clin Pharmacol. 1991;32(1):17-21 Epub 1991/07/01.

23. Carr A, Samaras K, Chisholm DJ, Cooper DA. Pathogenesis of HIV-1-protease inhibitor-associated peripheral lipodystrophy, hyperlipidaemia, and insulin resistance. Lancet. 1998;351(9119):1881-3 Epub 1998/07/04.

24. Menezes CN, Maskew M, Sanne I, Crowther NJ, Raal FJ. A longitudinal study of stavudine-associated toxicities in a large cohort of South African HIV infected subjects. BMC Infect Dis. 2011;11:244 (Epub 2011/09/20).

25. ter Hofstede HJ, Koopmans PP, Burger DM. Stavudine plasma concentrations and lipoatrophy. J Antimicrob Chemother. 2008;61(4):933-8 Epub 2008/02/19.

26. Viraben R, Aquilina C. Indinavir-associated lipodystrophy. AIDS. 1998;12(6):F37-9 Epub 1998/05/16.

27. Dube NM, Summers R, Tint KS, Mayayise G. A pharmacovigilance study of adults on highly active antiretroviral therapy, South Africa: 2007-2011. Pan Afr Med J. 2012;11:39 Epub 2012/05/18.

28. Boulle A, Orrel C, Kaplan R, Van Cutsem G, McNally M, Hilderbrand K, et al. Substitutions due to antiretroviral toxicity or contraindication in the first 3 years of antiretroviral therapy in a large South African cohort. Antivir Ther. 2007;12(5):753-60 Epub 2007/08/24.

29. Elzi L, Marzolini C, Furrer H, Ledergerber B, Cavassini M, Hirschel B, et al. Treatment modification in human immunodeficiency virus-infected individuals starting combination antiretroviral therapy between 2005 and 2008. Arch Intern Med. 2010;170(1):57-65 Epub 2010/01/13.

30. Lodwick RK, Smith CJ, Youle M, Lampe FC, Tyrer M, Bhagani $\mathrm{S}$, et al. Stability of antiretroviral regimens in patients with viral suppression. AIDS. 2008;22(9):1039-46 Epub 2008/06/04.

31. Kumarasamy N, Vallabhaneni S, Cecelia AJ, Yepthomi T, Balakrishnan P, Saghayam S, et al. Reasons for modification of generic highly active antiretroviral therapeutic regimens among patients in southern India. J Acquir Immune Defic Syndr. 2006;41(1):53-8 Epub 2005/12/13.

32. Bayou T, Woldu M, Meskel GG, Mezgebe H. Factors determinant for change of initial antiretroviral treatment regimen among patients on ART follow-up clinic of Mekelle Hospital, Mekelle. Ethiop J Basic Clin Pharmacol. 2014;3(1):44-9.

33. Hawkins C, Achenbach C, Fryda W, Ngare D, Murphy R. Antiretroviral durability and tolerability in HIV-infected adults living in urban Kenya. J Acquir Immune Defic Syndr. 2007;45(3):304-10 Epub 2007/04/07.

34. Maggiolo F, Arici C, Airoldi M, Ripamonti D, Quinzan G, Gregis $\mathrm{G}$, et al. Reasons for discontinuation of nevirapine-containing HAART: results from an unselected population of a large clinical cohort. J Antimicrob Chemother. 2007;59(3):569-72 Epub 2007/01/27.

35. Padua CA, Cesar CC, Bonolo PF, Acurcio FA, Guimaraes MD. High incidence of adverse reactions to initial antiretroviral 
therapy in Brazil. Braz J Med Biol Res = Revista brasileira de pesquisas medicas e biologicas / Sociedade Brasileira de Biofisica [et al]. 2006;39(4):495-505 (Epub 2006/04/14).

36. Sivadasan A, Abraham OC, Rupali P, Pulimood SA, Rajan J, Rajkumar S, et al. High rates of regimen change due to drug toxicity among a cohort of South Indian adults with HIV infection initiated on generic, first-line antiretroviral treatment. J Assoc Phys India. 2009;57:384-8 Epub 2009/07/29.

37. Tadesse WT, Mekonnen AB, Tesfaye WH, Tadesse YT. Selfreported adverse drug reactions and their influence on highly active antiretroviral therapy in HIV infected patients: a cross sectional study. BMC Pharmacol Toxicol. 2014;15:32 Epub 2014/06/25

38. Teklay G, Legesse B, Legesse B. Adverse effects and regimen switch among patients on antiretroviral treatment in a resource limited setting in Ethiopia. J Pharmacovigilance. 2013;1(4):115.

39. Friedland GH. Adherence: the Achilles' heel of highly active antiretroviral therapy. Improv Manag HIV Dis. 1997;5:13-5.

40. Subbaraman R, Chaguturu SK, Mayer KH, Flanigan TP, Kumarasamy N. Adverse effects of highly active antiretroviral therapy in developing countries. Clin Infect Dis. 2007;45(8):1093-101 Epub 2007/09/21.

41. WHO. Scaling up antiretroviral therapy in resource-limited settings: treatment guidelines for a public health approach. Geneva: 2004.

42. Max B, Sherer R. Management of the adverse effects of antiretroviral therapy and medication adherence. Clin Infect Dis. 2000;30(Suppl 2):S96-116 Epub 2000/06/22.

43. WHO. Consolidated Guidelines on the use of antiretroviral drugs for treating and preventing HIV infection: recommendations for a public health approach. Geneva: World Health Organization, 2013 June 2013. Report No.

44. Ssali F, Stohr W, Munderi P, Reid A, Walker AS, Gibb DM, et al. Prevalence, incidence and predictors of severe anaemia with zidovudine-containing regimens in African adults with HIV infection within the DART trial. Antivir Ther. 2006;11(6):741-9 (Epub 2007/02/22). 